\title{
Through-Knee Amputation-Time to Recall the Neglected Technique
}

\author{
Aadithya Rangarajan ${ }^{1}$ (D) B Baskara K.G ${ }^{1}$ (])
}

Received: 10 January 2022 / Accepted: 26 January 2022 / Published online: 31 January 2022

(c) Association of Surgeons of India 2022

COVID-19 pandemic, over the last 2 years, has changed the management of elective and emergency surgeries. With increasing number of infected patients getting hospitalised, the onus lies on the treating physicians and/or surgeons and the hospital staff to prevent transmission among the hospital personnel and keep themselves safe. We present the option of through-knee amputation, a neglected alternative, in a COVID-positive patient who required an emergency lower limb major amputation.

An elderly gentleman, with history of uncontrolled diabetes, systemic hypertension, ischemic heart disease, CVA and severe lower limb peripheral arterial disease, presented with necrotising fasciitis and gangrene of the right leg. CT angiogram reported total occlusion of the right femoral artery up to popliteal artery. He was diagnosed to be in sepsis and the right lower limb gangrene appeared life threatening. Therefore, an emergency right-sided above-knee amputation was advised. The prevailing critical condition of the patient was further worsened with positive COVID status and respiratory distress.

It has been shown that risk of COVID transmission increases with longer exposure time [1]. It is imperative any surgical intervention has to be performed with just the required members of the surgical and anaesthesia team and in shorter duration [2]. On an average, it takes 90-120 min to perform above-knee amputation and is technically more challenging especially wearing the personal protection equipment (PPE). Keeping these criteria in mind, we decided to do a standard through-knee amputation, a technique which is less preferred due to possible disadvantages namely delayed healing and difficulty in fitting the prosthesis [3].

$\mathrm{He}$ underwent the planned procedure after obtaining the appropriate informed high risk consent from the family. The surgery was completed in $45 \mathrm{~min}$. Postoperatively, there was a remarkable improvement of his condition from sepsis. He was thereafter shifted from the intensive care unit to the

Aadithya Rangarajan

aadidoc14@gmail.com

1 Department of Plastic and Reconstructive Surgery, Medical Trust Hospital, Kochi, Kochi, Ernakulam, Kerala 682016, India
COVID isolation ward for the further management of the viral infection. The amputated leg stump will be revised once the patient is fit for the surgery.

The advantages of the procedure over guillotine or definite above-knee amputation are relatively atraumatic, minimal soft tissue severance, no high energy bone saw and easy accessibility to the major neurovascular bundles (popliteal/tibioperoneal trunk, common peroneal nerve) [4]. Soft tissue coverage is performed at a faster pace considering the small surface area and therefore less operating time. In addition to minimising the exposure time among the surgery and anaesthesia team as well as occupation of the operating room, the burden of sepsis on the patient is lessened to a larger extent immediately. Revision of the stump is advocated once the patient recovers from the critical condition.

Through-knee amputation is a less favoured life-saving procedure over above-knee amputation but is certainly a feasible surgical technique to be considered in patients during certain circumstances such as the COVID pandemic.

\section{References}

1. Ge Y, Martinez L, Sun S et al (2021) COVID-19 transmission dynamics among close contacts of index patients with COVID19: a population-based cohort study in Zhejiang Province. China JAMA Intern Med 181(10):1343-1350. https://doi.org/10.1001/ jamainternmed.2021.4686

2. Liu Z, Zhang Y, Wang X, Zhang D, Diao D, Chandramohan K, Booth CM (2020) Recommendations for surgery during the novel coronavirus (COVID-19) epidemic. Indian J Surg. https://doi.org/ 10.1007/s12262-020-02173-3

3. Crane H, Boam G, Carradice D, Vanicek N, Twiddy M, Smith GE (2021) Through-knee versus above-knee amputation for vascular and non-vascular major lower limb amputations. Cochrane Database of Systematic Review. https://doi.org/10.1002/14651858. CD013839.pub2

4. Lim S, Javorski MJ, Halandras PM, Aulivola B, Crisostomo PR (2018) Through-knee amputation is a feasible alternative to above-knee amputation. J Vasc Surg 68(1):197-203. https://doi. org/10.1016/j.jvs.2017.11.094

Publisher's Note Springer Nature remains neutral with regard to jurisdictional claims in published maps and institutional affiliations. 